\title{
Progressive Collapse Analysis of Power Transmission Tower Under Earthquake Excitation
}

\author{
Li Tian*,1, Ruisheng Ma ${ }^{1}$, Wenming Wang ${ }^{2}$ and Lei Wang ${ }^{3}$ \\ ${ }^{1}$ School of Civil and Hydraulic Engineering, Shandong University, Jinan, Shandong, 250061, China \\ ${ }^{2}$ Faculty of Infrastructure Engineering, Dalian University of Technology, Dalian, Liaoning, 116024, China \\ ${ }^{3}$ Sichuan Institute of Building Research, Chengdu, Sichuan, 610081, China
}

\begin{abstract}
Collapses of power transmission towers had usually taken place in previous large earthquake. The collapse process of a power transmission tower under earthquake excitation is studied in this paper. Using international finite element software ABAQUS, the three-dimensional finite element model of the power transmission tower is created based on a practical engineering. Three typical seismic records are selected. The progress collapse processes of the power transmission tower under different seismic excitations are simulated using the nonlinear time history method. The collapse paths and failure positions of the power transmission tower are obtained under different seismic excitations. The results can provide reference for seismic design of power transmission tower which can prevent the collapse of the power transmission tower.
\end{abstract}

Keywords: Power transmission tower, seismic loading, finite-element model, the longitudinal and transverse collapse path, collapse process.

\section{INTRODUCTION}

With the development of the national economy, the demand for electric power is increasing. Transmission tower-line system is an important lifeline project [1]. Most of the transmission lines cross the high-intensity earthquake zones in China. The failure of the power transmission tower under earthquake seismic will affect the supply of electricity, causing huge economic losses and secondary disasters. There are several cases of damage to transmission lines during the earthquake. In 1999, the Chi-Chi earthquake caused huge destroy to electric power system with 69 transmission lines destroyed, 15 towers collapsed and 26 towers inclined. During 2008 Wenchuan earthquake, more than 20 towers of the $110 \mathrm{kV}$ transmission line collapsed and all towers of one $220 \mathrm{kV}$ transmission line in Mao County destroyed severely. So it is important to make sure the safety of power transmission towers in the earthquake.

In the past two decades, researchers have done some analysis of the transmission tower-line system under earthquake seismic. Li et al. [2] studied the plastic limit of transmission tower using ANSYS software; Tian et al. [3] studied the transverse response of transmission tower-line system under multiple support excitations, considering the nonlinearity of transmission lines. Quan et al. [4] studied the

*Address correspondence to this author at the School of Civil and Hydraulic Engineering, Shandong University, Jinan, Shandong, 250061, China;

Tel: +86 531-88396182; Fax:+86 531-88392843;

E-mail: tianl-007@163.com longitudinal response of a power transmission tower-line system under multi-support excitations by nonlinear time history analysis. Yue et al. [5] studied the longitudinal response of the power transmission tower-line system under multiple seismic excitations considering the effect of traveling wave. But there is no research about the progressive collapse analysis of power transmission tower under earthquake excitation.

Progressive collapse process of power transmission tower is analyzed by defining the fracture strain of member in the ABAQUS finite element software. The collapse routine, collapse mechanism and collapse resistance capacity of structure can be determined by progressive collapse analysis. The result of the collapse analysis can provide reference for the seismic design of the power transmission tower.

\section{COLLAPSE ANALYSIS METHOD}

Considering the size of power transmission tower and current test conditions, it is not realistic to study the collapse process of scaled tower model in laboratory. Numerical simulation method is widely used in the research field of progressive collapse. Compared to scale model tests, the result of numerical simulation method is accurate with reasonable cost. Now, there are mainly three numerical analytical methods including the discrete element method, the finite element method and the combined finite-discrete element method. 


\subsection{Introduction of Three Numerical Simulation Methods}

Theoretically speaking, the discrete element method is the most appropriate approach for collapse analysis, because element is discontinuous in the process of collapse. But, the large-scale application of the method is difficult owing to the lack of theory, lower efficiency and no professional software [6-7].

The finite element method is now widely used in the solution of large scale industrial problems [8]. Based on whether a new value is related to other new values in each increment step, the finite element method can be divided into explicit finite element method and implicit finite element method. Compared to implicit finite element method, the explicit finite element method can easily solve complex contact problems with low CPU cost.

The combined finite-discrete element method is an emerging numerical simulation method. Using the method, total behaviors of structures from zero loading to collapse can be followed with reliable accuracy and reasonable CPU time [9]. But the application of the method is greatly limited due to the absence of efficient software.

\subsection{Proposed Method}

Compared to the other two methods, the finite element method is suitable for the collapse analysis of structure. The collapse process of power transmission tower is analyzed by defining fracture strain of materials, using explicit finite element function of software ABAQUS. In analysis, if an element loses bear-loading capability, it will be removed in structure. Along with the action of seismic waves, more and more elements will lose bear-loading capability, leading to the collapse of power transmission tower.

\section{CALCULATION MODEL}

The tower used for present study was $500 \mathrm{kV}$ double-circuit and four-bundle line tower in Liaoning, China. The base width and height of the tower are $9.36 \mathrm{~m}$ and $53.9 \mathrm{~m}$, respectively. The size and the first two modals of the power transmission tower are illustrated in Fig. (1). Main members of the tower are made of Q345, and secondary members are made of Q235. Only the leg and primary bracings are considered in analysis, using ABAQUS three dimensional beam elements type B31 with three translational and three rotational degrees of freedom per node. The material nonlinearity were taken into consideration.

\section{PROGRESS COLLAPSE ANALYSIS OF POWER TRANSMISSION TOWER}

\subsection{Selection of Seismic Wave}

Three typical horizontal seismic waves are selected according to the code for design of seismic of electrical installations (GB 50260-96) [10]. In Fig. (2), there are three typical seismic waves selected: (a) El Centro wave; (b) Kobe wave; (c) Northridge wave. To obtain the collapse process of the

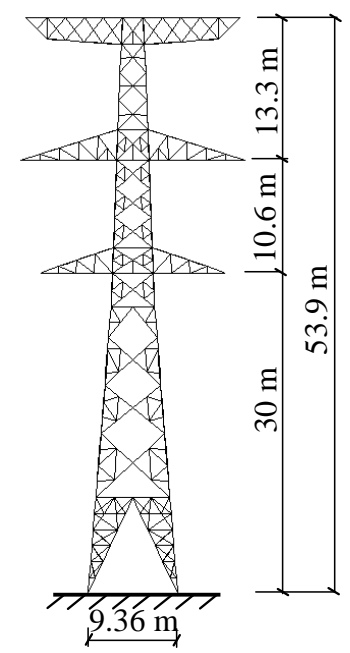

(a) Tower size

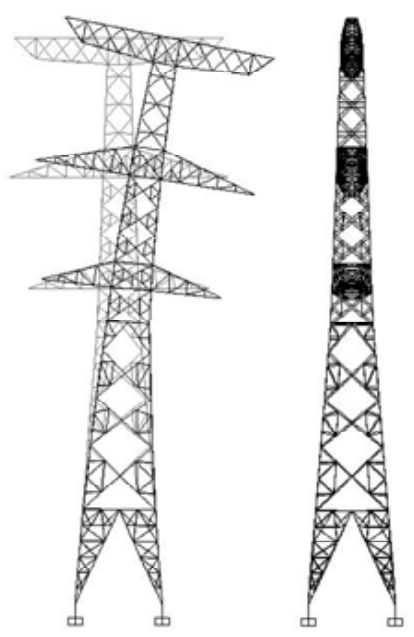

(b) The first modal

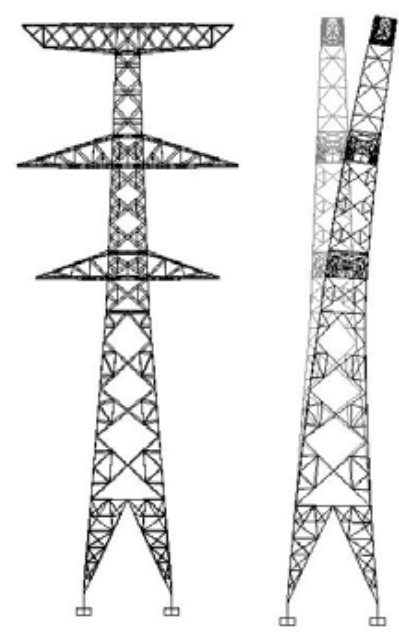

(c) The second modal

Fig. (1). Tower size and the first two modals of the power transmission tower. 


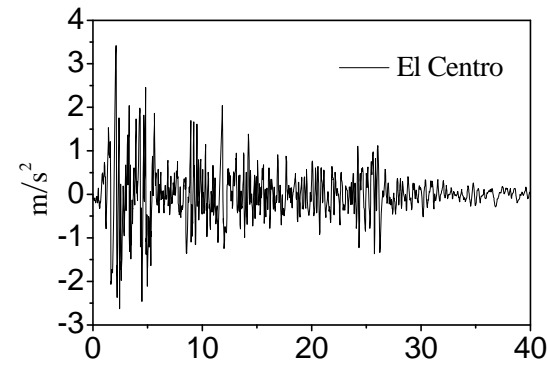

(a) El Centro wave

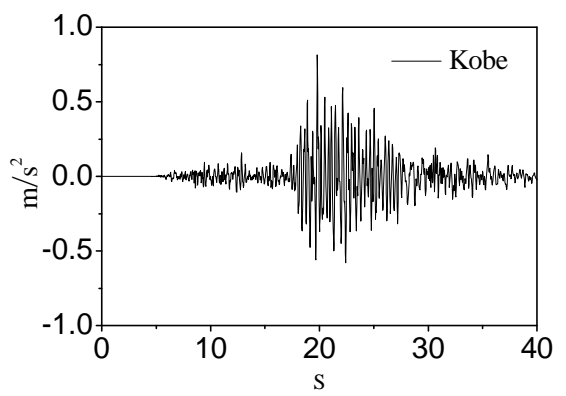

(b) Kobe wave

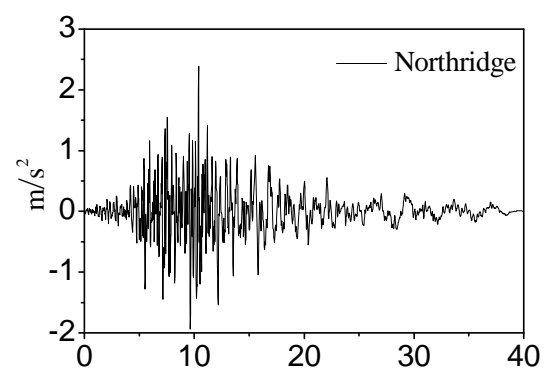

(c)Northridge wave

Fig. (2). The selection of seismic waves

model, the peak ground accelerations are set equal to $11 \mathrm{~m} / \mathrm{s}^{2}$, $10 \mathrm{~m} / \mathrm{s}^{2}$ and $10 \mathrm{~m} / \mathrm{s}^{2}$ respectively. Every seismic wave is inputted along longitudinal or transverse direction of tower, respectively.

\subsection{Collapse analysis Along Longitudinal Direction}

Seismic waves are only inputted along longitudinal direction of the power transmission tower. Collapse processes of the tower under El Centro wave, Kobe wave and Northridge wave are shown in Figs. (3-5) respectively.

In Fig. (3), the longitudinal collapse process of power transmission tower under El Centro seismic wave is shown. An element of main leg at $Z=32.40 \mathrm{~m}$ yielded first at $5.18 \mathrm{~s}$. Elements of main leg and diagonal bracings at $Z=28.45 \mathrm{~m}$ lost load-bearing capability at $5.19 \mathrm{~s}$. The vertical load transfer path of tower was destroyed completely at 5.30s. Then structure entered the stage of rapid collapse.

As shown in Fig. (4), the longitudinal collapse process of power transmission tower under Kobe seismic wave is illustrated. At $\mathrm{t}=29.92 \mathrm{~s}$, an element of main leg at $\mathrm{Z}=32.40 \mathrm{~m}$ yielded first. From 29.92s to 30.65 s, the elements between $\mathrm{Z}=32.4 \mathrm{~m}$ and $\mathrm{Z}=40.6 \mathrm{~m}$ lost load-bearing capability gradually. After the destruction of the power transmission tower's vertical load transfer path, the upper part of structure entered the stage of rapid collapse. At $\mathrm{t}=31.12$, cross arm at $\mathrm{Z}=30 \mathrm{~m}$ lost load-bearing capability.

The longitudinal collapse process of power transmission tower under Northridge seismic wave is shown in Fig. (5). An element of main leg at $Z=15 \mathrm{~m}$ yielded first at $16.52 \mathrm{~s}$. Diagonal bracings at $\mathrm{Z}=24 \mathrm{~m}$ lost load-bearing capability at 16.82s. The vertical load transfer path of the power transmission tower is completely destroyed at $17.32 \mathrm{~s}$. But few elements above $24 \mathrm{~m}$ height lost load-bearing capability at the same time.

In progressive longitudinal collapse process of the tower under El Centro seismic wave and Kobe seismic wave, elements of main leg at $\mathrm{Z}=32.40 \mathrm{~m}$ are fracture position. During progressive longitudinal collapse process of the tower under Northridge seismic wave, elements of main leg at $Z=15 \mathrm{~m}$ are fracture position. The fracture positions and longitudinal collapse paths of power transmission tower are different under various seismic waves.

\subsection{Collapse Analysis Along Transverse Direction}

Seismic waves are only inputted along transverse direction of the power transmission tower. Collapse process of the tower under El Centro seismic wave, Kobe seismic wave and Northridge seismic wave are shown in Figs. (6-8) respectively.

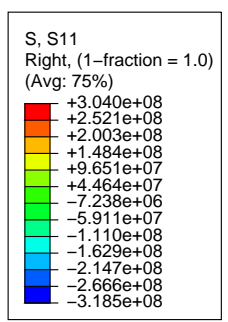

(a) $\mathrm{t}=5.18 \mathrm{~s}$
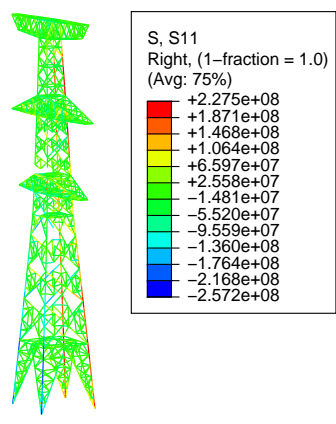

(b) $t=5.30 \mathrm{~s}$

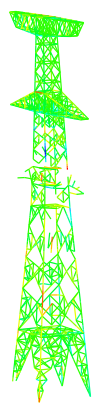

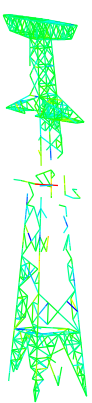

(c) $\mathrm{t}=5.50 \mathrm{~s}$

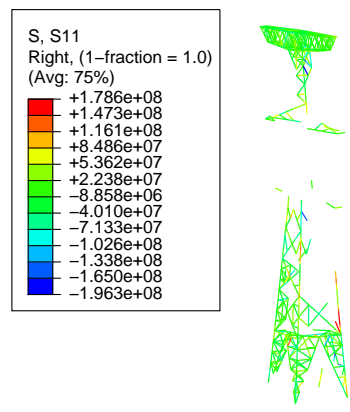

(d) $\mathrm{t}=5.70 \mathrm{~s}$

Fig. (3). Collapse process of tower along longitudinal direction under El Centro seismic wave. 
The transverse collapse process of power transmission tower under El Centro seismic wave is given in Fig. (6). At $4.67 \mathrm{~s}$, an element of main leg at $\mathrm{Z}=32.40 \mathrm{~m}$ yielded first. $\mathrm{T}=4.71 \mathrm{~s}$, the vertical load transfer path of the tower lost and upper structure entered the stage of rapid collapse. At 5.12s, a bracing component of diaphragm at $\mathrm{Z}=26.80 \mathrm{~m}$ lost bear-loading capability and the entire structure began to collapse rapidly.

Fig. (7) gives the transverse collapse of power transmission tower under Kobe seismic wave. Elements of main leg at $\mathrm{Z}=32.40 \mathrm{~m}$ yielded at $\mathrm{t}=23.56 \mathrm{~s}$. The vertical load transfer path of tower was destroyed at 23.68s. Upper structure and cross arm at $\mathrm{Z}=30 \mathrm{~m}$ began to lose bear-loading capability at the same time. At 26.8s, a bracing component of diaphragm at
$\mathrm{Z}=26.80 \mathrm{~m}$ lost bear-loading capability. At 25.03s, all bracing components of diaphragm destroyed.

In Fig. (8), the transverse collapse process of power transmission tower under Northridge seismic wave is illustrated. Diagonal bracings at $\mathrm{Z}=22.875 \mathrm{~m}$ yielded at $12.94 \mathrm{~s}$ and more peripheral diagonal bracing yielded subsequently. An element of main leg at $Z=15 \mathrm{~m}$ lost load-bearing capability at $14.62 \mathrm{~s}$.

In progressive transverse collapse process of the tower under El Centro seismic wave and Kobe seismic wave, elements of main leg at $\mathrm{Z}=32.40 \mathrm{~m}$ are fracture position. During progressive transverse collapse process of the tower under Northridge seismic wave, diagonal bracings at $\mathrm{Z}=22.875 \mathrm{~m}$

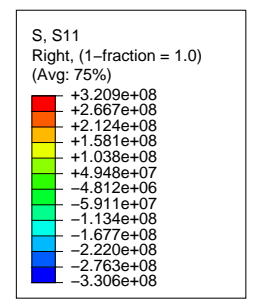

(a) $t=29.9 s$

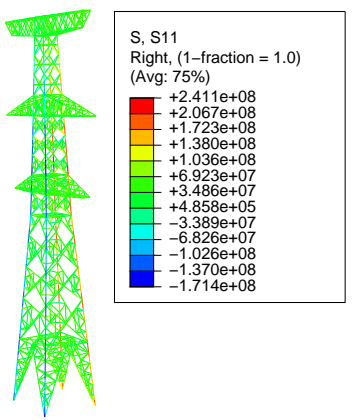

(b) $t=30.0 \mathrm{~s}$
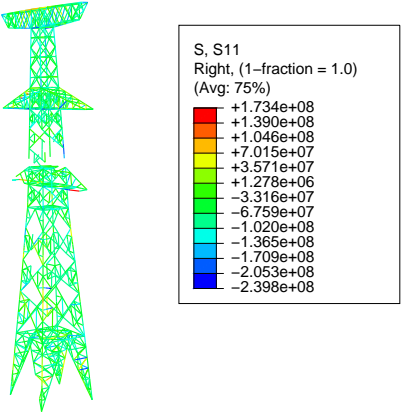

(c) $t=30.3 \mathrm{~s}$
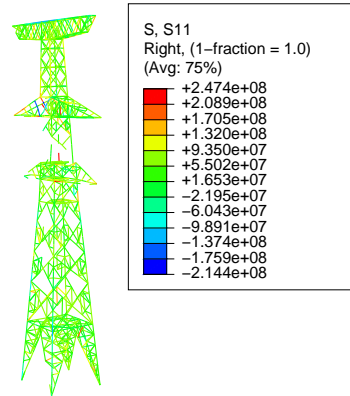

$-2.144 \mathrm{e}+08$

(d) $30.5 \mathrm{~s}$

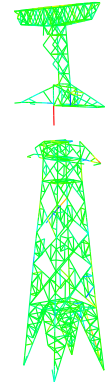

Fig. (4). Collapse process of tower along longitudinal direction under Kobe seismic wave.

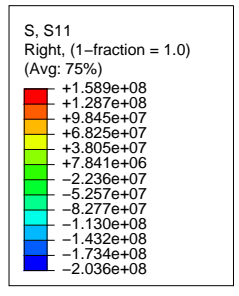

(a) $t=16.7 \mathrm{~s}$

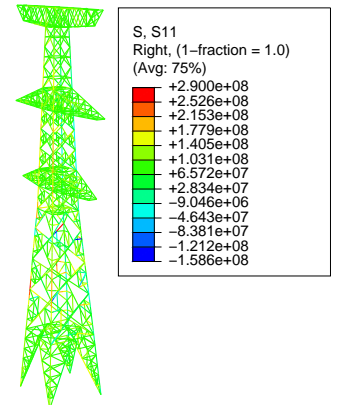

(b) $\mathrm{t}=16.9 \mathrm{~s}$
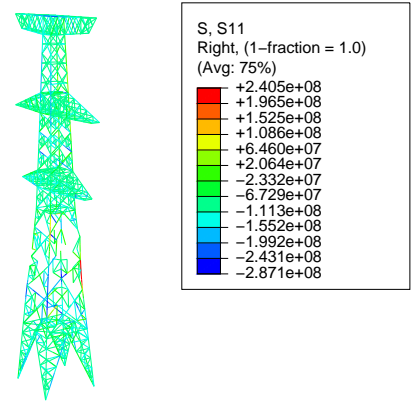

(c) $\mathrm{t}=17.0 \mathrm{~s}$
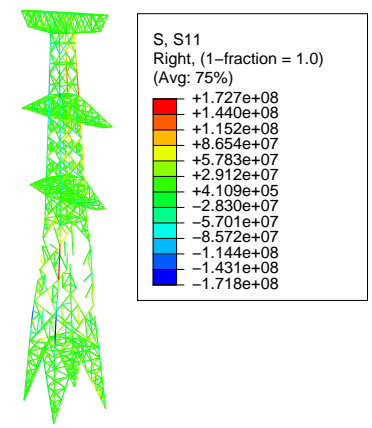

(d) $t=17.3 \mathrm{~s}$
Fig. (5). Collapse process of tower along longitudinal direction under Northridge seismic wave.

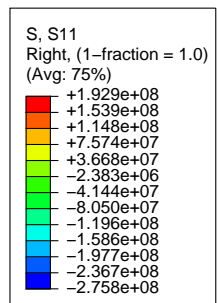

(a) $t=4.7 \mathrm{~s}$
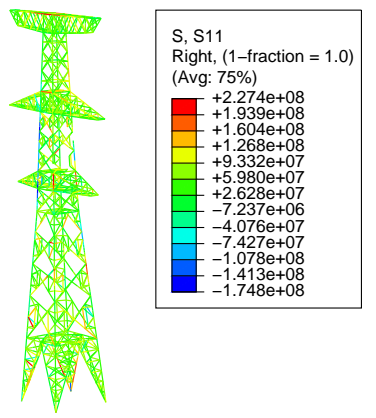

(b) $\mathrm{t}=5.0 \mathrm{~s}$
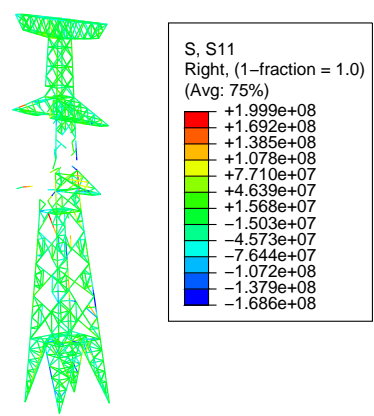

(c) $t=5.3 \mathrm{~s}$
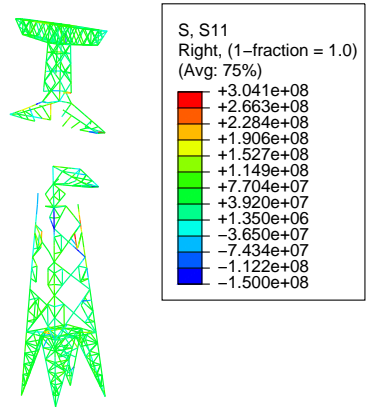

(d) $t=5.6 s$
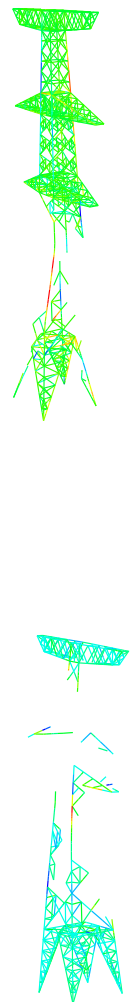

Fig. (6). Collapse process of tower along transverse direction under El Centro siemsic wave. 


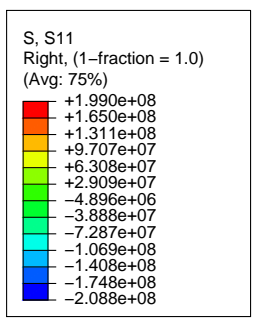

(a) $t=23.5 \mathrm{~s}$

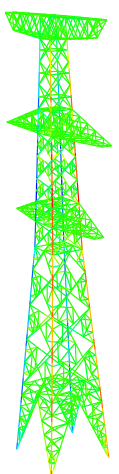

1

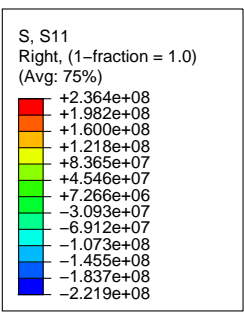

(b) $t=23.6 \mathrm{~s}$

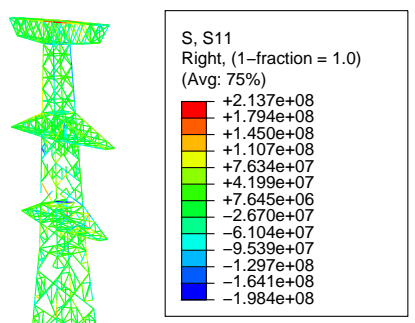

(c) $t=23.7 \mathrm{~s}$

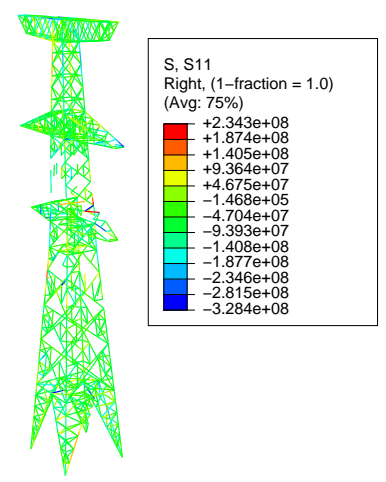

(d) $t=24 \mathrm{~s}$

Fig. (7). Collapse process of tower along transverse direction under Kobe siemsic wave.

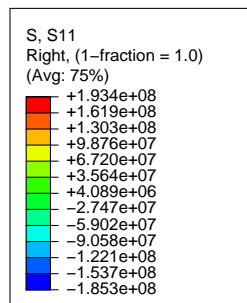

(a) $\mathrm{t}=14.0 \mathrm{~s}$

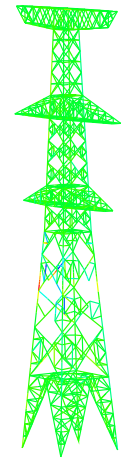

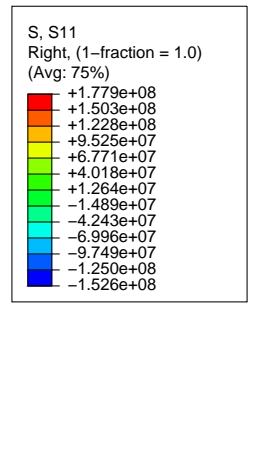

(b) $\mathrm{t}=14.7 \mathrm{~s}$
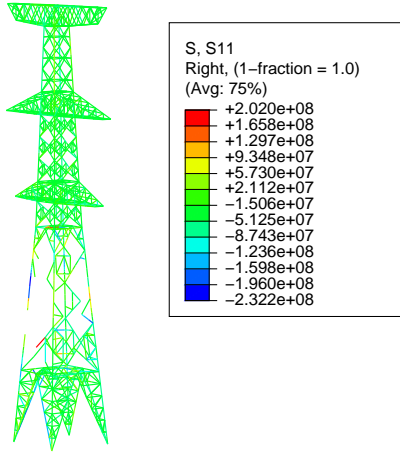

Fig. (8). Collapse process of tower along transverse direction under Northridge seismic wave

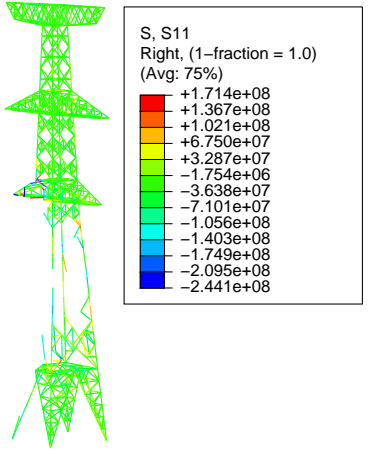

(d) $t=15.3 \mathrm{~s}$
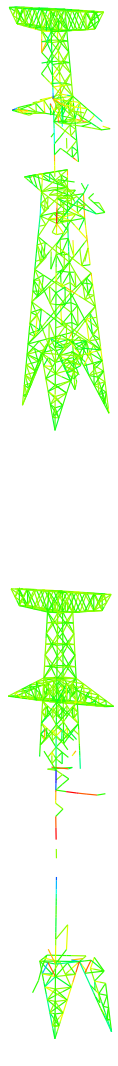

are fracture position. The fracture positions and transverse collapse paths of power transmission tower are different under various ground motions.

\section{CONCLUSIONS}

From progressive collapse analysis based on explicit finite element method of ABAQUS, the following conclusions are drawn:

(1) The method used in the paper is an efficient method of the collapse analysis.

(2) According to the collapse analysis, the failure position and collapse routine of the tower under seismic waves can be obtained.

(3) The longitudinal or transverse collapse paths are different under various seismic waves. Three or more seismic waves should be used for longitudinal or transverse collapse analysis.

(4) The result of collapse analysis can be used for the seismic design of power transmission tower and the reinforcement of current structures.

\section{CONFLICTS OF INTERESTS}

The authors confirm that this article content has no conflicts of interest.

\section{ACKNOWLEDGEMENTS}

This work is financially supported by the National Natural Science Foundation of China under grant No. 51208285, the China Postdoctoral Science Foundation funded project under grant No. 2012M521338 and Independent Innovation Foundation of Shandong University of China under No. 2011GN051. The supports for this research are greatly appreciated.

\section{REFERENCES}

[1] Q. Xie and J. Li, "Current situation of natural disaster in electric power system and counter measures”, Journal of Natural Disasters, vol. 15, pp.126-131, 2006. (in Chinese).

[2] H. N. Li, D. Z. Hu and L. Z. Huang, "Plastic limit analysis of the transmission tower system subjected to earthquake action", Proceedings of the CSEE, vol. 26, pp.192-199, 2006. (in Chinese).

[3] L. Tian, H. N. Li and L. Z. Huang, "Lateral response of transmission tower-line system under multiple support excitations”, Proceedings of the CSEE, vol. 28, pp.108-114, 2008. (in Chinese).

[4] W. Quan, H. N. Li and M. G. Yue, "Longitudinal response of a power transmission tower-cable system under multi-support excitations”, Journal of Vibration and Shock, vol. 27, pp.75-80, 2008. (in Chinese).

[5] M. G. Yue, H. N. Li and D. S. Wang, "Longitudinal response of the power transmission tower-cable system under traveling seismic wave excitations", Proceedings of the CSEE, vol. 26, pp.145-150, 2006 (in Chinese).

[6] K. X. Liu and L. T. Gao, "A review on the discrete element method", Advances in Mechanics, vol. 33, pp. 483-490, 2003. (in Chinese). 
[7] X. Q. Zhou, W. Y. Xu, X. Q. Niu and Y. Z. Cui, “A review of distinct element method researching progress and application”, Rock and Soil Mechanics, vol. 28, pp.408-416, 2007. (in Chinese).

[8] X. C. Wang, Finite Element Method. Beijing: Tsinghua University Press, 2003. (in Chinese).
[9] K. Meguro and H. Tagel-Din, “Applied element method for structural analysis: theory and application for linear materials”, Structural Eng. / Earthquake En. JSCE, vol. 17, pp.21-35, 2000.

[10] GB 50260-96. Code for Design of Seismic of Electrical Installations [S]. Beijing: China Planning Press, 1996. (in Chinese).

Received: May 30, 2013

(C) Tian et al.; Licensee Bentham Open.

This is an open access article licensed under the terms of the Creative Commons Attribution Non-Commercial License (http://creativecommons.org/licenses/by-nc/3.0/) which permits unrestricted, non-commercial use, distribution and reproduction in any medium, provided the work is properly cited. 